\title{
Strategic human resource management: A brief introduction
}

\section{Book Title:}

Short introduction to strategic human resource management

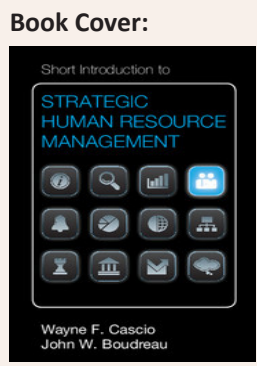

ISBN:

9781107608832

Publisher:

Cambridge University Press, 2012, US\$21.98*

*Book price at time of review -

\section{Review Title:}

Strategic human resource management: A brief introduction

\section{Reviewer:}

Jenni Gobind

\section{Affiliation:}

${ }^{1}$ Department of Industrial Psychology and People Management, University of Johannesburg, South Africa

Email:

jgobind@uj.ac.za

\section{Postal address:}

Postnet Suite 333, Private Bag X17, Weltevreden Park 1715 , South Africa

How to cite this article: Gobind, J. (2014). Strategic human resource management: A brief introduction. SA Journal of Human Resource Management/SA Tydskrif vir Menslike Hulpbronbestuur 12(1), Art. \#611, 2 pages. http://dx.doi.org/10.4102/ sajhrm.v12i1.611

\section{Read online:}

Short Introduction to strategic human resource management is a short and concise book written by Wayne Cascio and John Boudreau. This book is about human resource (HR) strategy: the decisions, processes and choices that organisations make about managing people. It is designed as a primer for students pursuing a master of business administration (MBA) degree or HR programs, as well as for HR and organisation leaders and general managers. It aims to provide an overview of the elements of human resource plans at the strategic, operational, unit and functional levels. This eightchapter book is succinct and to the point. Chapter 1 discusses the definition of strategy, strategy formulation analysing internal strengths and weakness and a brief history of strategic thought; this chapter makes reference to Michael Porter's influential thinking on corporate strategy. Cascio and Boudreau round up the chapter by discussing strategy today whilst investigating the aspect of strategic direction with an emphasis on vision, mission and objectives of organisations.

Chapter 2 examines some aspects of the external environments of organisations, whilst discussing globalisation. Cascio and Boudreau discuss the effects of globalisation and technology on labour markets whilst investigating legal, political and regulatory environments. Virtual mobility and new business models are touched on with reference to case studies like the Mumbai-based Tata Group, Apple and UPS. Chapter 3 discusses HR strategy in the context of environmental, organisational and functional elements. In this chapter the authors describe how HR strategy has to consider not just the HR department but its connection to the organisation and the surrounding environment. A multi-level framework for the context of HR strategy is unpacked, three observations are made: HR success will incorporate other disciplines, HR success will rely on boundary spanning and HR success will require accepting diverse definitions of the HR role. Once again the authors use a carefully selected case study that emphasises the gist of the chapter. In this instance, the authors relied on the Disney Company as an example in discussing risk management.

Chapter 4 investigates HR strategy through a risk-optimisation framework. This chapter focuses more explicitly on mitigating, managing and optimising human capital risk, and then incorporating these considerations into HR strategy. The chapter discusses human capital strategy as a risk mitigation, uncertainty, risk and opportunity and how risk and opportunity are related. The Chinese concept of 'ji' is expounded on, incorporating the idea of retooling risk in HR management using traditional management tools. The chapter ends with a summary, touching on uncertainty, risk and opportunity applied to employee turnover. Chapter 5 deals with HR strategy: linkages, anchor points and outcomes. This chapter provides a framework for understanding the connections between the investment that organisations make in human resource management and the vital outcomes that organisations define as sustainable strategic success. The chapter further delves into impact, effectiveness and efficiency, once again referring to the Disney Company and their talent pools, which make the biggest difference to strategic success.

Chapter 6 speaks of HR strategy: communication and engagement. This chapter emphasises the role of communication in talent engagement. Human capital reporting is widely discussed whilst making reference to principles of persuasion and human resource strategy communication, trust and communicating human capital strategy to employees. Starbucks aprons and the power of trust as the authors explain it are an example of power and the importance of employee perceptions to human capital strategy. How to communicate human capital with managers and leaders is effectively discussed using the Royal Bank of Canada as a basis for discussion. The chapter concludes by looking at strategy and transformative HR. Chapter 7 focuses on outcomes of successful business and HR strategies. The authors open this chapter with reference to chess and the role of strategy in the game of chess. The chapter pays attention to the balance score card from financial to strategic reporting, customer, internal business and innovative learning perspectives.

Chapter 8 looks at future forces driving HR strategy, the elements of HR strategy and a balanced approach to uncertainty and opportunity. This chapter recaps previous chapters by teasing out major

Copyright: () 2014. The Authors. Licensee: OpenJournals Publishing. This work is licensed under the Creative Commons Attribution License. 
themes like globalisation, driving innovation, using talent analytics and focusing on values. The authors conclude with a final word stating that they hope that the tools they have provided will help in the journey towards strategic Human Resource management. As Denise Rousseau, a university professor at Carnegie Mellon University, states:

Cascio and Boudreau have written a state-of-the art primer on how managers can learn to think systematically about human resource decisions. With concrete examples and cases, they show how to combine the best available business facts with scientific findings to improve the quality and strategic value of the organization's HR practices.

The authors have indeed taken a journey in using practical examples to guide the reader into a world of strategic human resource management. 